INTERVENTIONAL CARDIOLOGY AND SURGERY

\title{
Late reopening of an occluded infarct related artery improves left ventricular function and long term clinical outcome
}

\author{
F Piscione, G Galasso, G De Luca, G Marrazzo, G Sarno, O Viola, D Accardo, M Chiariello
}

Heart 2005;91:646-651. doi: 10.1136/hrt.2004.041152

See end of article for authors' affiliations

\section{Correspondence to:} Dr F Piscione, Via S Pansini, 5, 80131 Naples, Italy; piscione@unina.it

Accepted 9 August 2004
Objective: To assess effects on left ventricular (LV) function and on long term clinical outcome of late percutaneous transluminal coronary angioplasty (PTCA) of a chronically occluded infarct related artery. Methods: 65 patients who underwent PTCA a mean (SD) of 6.0 (1.2) months after a previous myocardial infarction were divided in two groups according to dilated artery patency status after PTCA: group 1 (35 patients with TIMI (thrombolysis in myocardial infarction) grade 3 flow) and group 2 ( 30 patients with TIMI grade 0-2 flow). Echocardiography was performed at admission and at six months' follow up. A three year follow up was conducted with major adverse cardiac events (MACE) as end points.

Results: At follow up, group 1 had improved global LV ejection fraction $(48.7 \% v 43.6 \%, p<0.001)$ and LV indexed end diastolic and end systolic volumes $\left(75 \vee 86 \mathrm{ml} / \mathrm{m}^{2}\right.$ and $40 \vee 53 \mathrm{ml} / \mathrm{m}^{2}$, respectively, $p=0.011)$ compared with group 2. Kaplan-Meier analysis showed a higher incidence of cardiac death $(p=0.02)$ and MACE $(p<0.0001)$ in group 2. TIMI 3 after PTCA was an independent predictor of event-free survival at follow up.

Conclusion: Late PTCA of a chronically occluded infarct related artery improves LV function, reduces cardiac death, and improves long term clinical outcome.
$\mathrm{E}$ arly restoration of coronary artery patency and its persistence are important goals of treatment of myocardial infarction (MI), since it has been shown that complete (TIMI (thrombolysis in myocardial infarction) grade 3 flow) restoration of infarct related artery (IRA) flow leads to improved left ventricular (LV) function, reduced in-hospital mortality, ${ }^{12}$ and improved long term clinical outcome. ${ }^{3-5}$ Several experimental models have shown that late reperfusion prevents infarct expansion and LV dilatation. ${ }^{67}$ The open artery hypothesis suggests that delayed recanalisation of IRA may also be beneficial ${ }^{8}$ by limiting infarct expansion, reducing LV dilatation, and improving survival. ${ }^{9}$ Although this hypothesis has been investigated in several trials of thrombolytics for late treatment of patients with acute MI (so called late reperfusion), ${ }^{10}{ }^{11}$ only few and conflicting data have been reported so far evaluating the effects of IRA reopening several days after the acute event. ${ }^{12}{ }^{13}$ Recent studies $^{14}{ }^{15}$ have shown the beneficial effect of late reperfusion on preventing LV dilatation and improving function in a well defined group of patients with occlusion of the left anterior descending coronary artery. These findings suggest that there is a short time window of only a few weeks after the acute event during which the myocardium may still be salvaged and LV remodelling can be prevented. Furthermore, these studies enrolled highly selected patients representing only a small percentage $(<3 \%$ as suggested by Pfisterer and colleagues ${ }^{15}$ ) of all patients with an MI. Concerning the role of late IRA reopening by percutaneous transluminal coronary angioplasty (PTCA) in unselected patients, so far only few and conflicting data are available. Thus, this study aimed at evaluating the effects of late reopening of a chronically occluded IRA on global and regional LV function and on the long term clinical outcome in unselected patients.

\section{METHODS}

\section{Study population}

From January 1996 to February 1997, 65 consecutive patients with previous transmural MI and ischaemic symptoms (angina classified according to Canadian Cardiovascular Society) or the presence of either ischaemia or myocardial viability in the myocardial territory subtended by a total occlusion $^{16}$ as previously described were admitted to our catheterisation laboratory to undergo PTCA of the chronically occluded IRA. No patients had been treated by PTCA or thrombolysis at the time of the index MI.

\section{Angioplasty procedure}

Written informed consent was obtained from all patients before the procedure. PTCA was attempted through the femoral artery with a 7 French guiding catheter. All patients underwent PTCA of the chronically occluded IRA a mean (SD) of 6.0 (1.2) months after a documented episode of transmural MI. Patients were pretreated with aspirin $300 \mathrm{mg}$ and received $5000 \mathrm{U}$ of heparin intravenously at the beginning of the procedure. A chronic coronary total occlusion was defined as a coronary artery with $100 \%$ prePTCA luminal narrowing without antegrade flow or with either antegrade or retrograde filling through collateral vessels. Antegrade perfusion of the IRA was graded by TIMI criteria ${ }^{17}$ and collateral flow was scored according to the Rentrop classification. ${ }^{18}$ Technical success was defined as crossing the lesion with a wire and a balloon and restoring antegrade flow regardless of the percentage of the residual stenosis. Clinical success was defined when the occlusive lesion was reduced to $<20 \%$ diameter stenosis with restoration of optimal antegrade flow defined as TIMI grade 3 flow. Two groups were defined according to their dilated artery patency status after PTCA:

Abbreviations: EDVi, end diastolic volume index; $E S V i$, end systolic volume index; IRA, infarct related artery; LV, left ventricular; LVEF, left ventricular ejection fraction; MACE, major adverse cardiac events; $M \mathrm{I}$, myocardial infarction; PTCA, percutaneous transluminal coronary angioplasty; TIMI, thrombolysis in myocardial infarction; WMSI, wall motion score index 
- Group 1: 35 patients with TIMI grade 3 flow

- Group 2: 30 patients with TIMI grade 0-2 flow.

After the procedure all patients were treated with aspirin $325 \mathrm{mg} /$ day and ticlopidine $250 \mathrm{mg}$ orally twice daily for one month. No patients received glycoprotein IIb/IIIa receptor blockers.

\section{Echocardiography}

All patients underwent standard $\mathrm{M}$ mode and two dimensional echocardiography followed by colour flow imaging and pulsed and continuous wave Doppler ultrasound study on admission (basal, two days before PTCA) and at six months' follow up. A phased array electronic ultrasound system (SONOS 1000, Hewlett Packard) with a $2.5 \mathrm{MHz}$ transducer was used and gain settings were adjusted to optimise the definition of endocardial borders. End diastolic and end systolic volumes were calculated by the biplane area-length method $^{1920}$ and corrected for body surface area to be expressed as volume indexes (EDVi and ESVi, respectively). LV systolic frames were obtained from the parasternal short axis view at the level of the papillary muscles and from the apical four and two chamber views. Left ventricular ejection fraction (LVEF), as an index of global LV function, and wall motion score index (WMSI), scored according to the 16 segment model from 1 (normal) to 3 (akinetic) at each segment, were determined by two independent operators blinded to clinical and angiographic data. There was $<4 \mathrm{ml}$ interobserver $(r=0.75)$ and $<2 \mathrm{ml}$ intraobserver variability in LV volume measurements, and $<5 \%(r=0.83)$ interobserver and $<4 \%$ intraobserver variability in global LVEF measurements.

\section{Clinical follow up}

Long term clinical outcome considered the following major adverse cardiac events (MACE) as end points: cardiac death, acute MI, repeat PTCA of the target vessel, bypass surgery involving the treated vessel, and development of congestive heart failure. The follow up was based on a direct systematic review of all patients' clinical files during the study period and by telephone or direct patient interviews 36 months after PTCA. We also contacted relatives or a patient's physician when necessary. Follow up was obtained for all patients and data were stored in our database.

\section{Statistical analysis}

Continuous variables are presented as mean (SD) and categorical variables as absolute number and percentage. Two way analysis of variance for repeated measures was used. Differences between groups were assessed with univariate analysis of variance for continuous variables and with a $\chi^{2}$ test with the Fisher exact test and odds ratio with 95\% confidence intervals for categorical variables; $\mathrm{p}<0.05$ was considered significant. Interobserver and intraobserver reproducibility was analysed by the Bland-Altman method. Difference in event-free survival between the groups were evaluated by the Kaplan-Meier method and compared by the $\log$ rank test. Multivariate analysis was performed to determine the independent predictor of long term survival. Baseline demographic (age and sex), clinical (risk factors, Killip class at the time of the index MI), and angiographic features (grading of collateral flow, TIMI flow before and after PTCA, treated vessel, presence of multivessel disease) and ventricular function (LVEF and WMSI) were entered into the model to explore effects of any of these factors on outcome. The computer program used was SPSS version 11.1 (SPSS, Inc, Chicago, Illinois, USA).
Table 1 Baseline characteristics of patients with TIMI 3 (group 1) and TIMI 0-2 (group 2) flow after PTCA

\begin{tabular}{|c|c|c|c|}
\hline & $\begin{array}{l}\text { Group } 1 \\
(n=35)\end{array}$ & $\begin{array}{l}\text { Group } 2 \\
(n=30)\end{array}$ & p Value \\
\hline Age (years) & $58(10)$ & $54(9)$ & NS \\
\hline Male sex & $87 \%$ & $81 \%$ & NS \\
\hline Family history of CAD & $45 \%$ & $48 \%$ & NS \\
\hline Hypercholesterolaemia & $26 \%$ & $26 \%$ & NS \\
\hline Diabetes & $18 \%$ & $15 \%$ & NS \\
\hline Hypertension & $13 \%$ & $16 \%$ & NS \\
\hline Smoking & $26 \%$ & $25 \%$ & NS \\
\hline Previous anterior $\mathrm{Ml}$ & $55 \%$ & $52 \%$ & NS \\
\hline Time from index MI to PTCA (months) & $6(2)$ & $6(1)$ & NS \\
\hline \multicolumn{4}{|l|}{ Killip class } \\
\hline 1 & $5 \%$ & $4 \%$ & NS \\
\hline$\|$ & $75 \%$ & $78 \%$ & NS \\
\hline III & $20 \%$ & $18 \%$ & NS \\
\hline \multicolumn{4}{|l|}{ NYHA class } \\
\hline I & $15 \%$ & $12 \%$ & NS \\
\hline$\|$ & $78 \%$ & $80 \%$ & NS \\
\hline III & $7 \%$ & $8 \%$ & NS \\
\hline \multicolumn{4}{|l|}{ Treatment before PTCA } \\
\hline Anticoagulants & $10 \%$ & $12 \%$ & NS \\
\hline Antiplatelets & $85 \%$ & $83 \%$ & NS \\
\hline$\beta$ Blockers & $45 \%$ & $48 \%$ & NS \\
\hline ACE inhibitors & $11 \%$ & $10 \%$ & NS \\
\hline Calcium channel blockers & $38 \%$ & $36 \%$ & NS \\
\hline \multicolumn{4}{|l|}{ Treatment at discharge } \\
\hline Anticoagulants & $11 \%$ & $14 \%$ & NS \\
\hline Antiplatelets & $98 \%$ & $100 \%$ & NS \\
\hline$\beta$ Blockers & $82 \%$ & $84 \%$ & NS \\
\hline ACE inhibitors & $40 \%$ & $45 \%$ & NS \\
\hline Calcium channel blockers & $16 \%$ & $22 \%$ & NS \\
\hline \multicolumn{4}{|c|}{$\begin{array}{l}\text { Data are mean (SD) or percentage. } \\
\text { ACE, angiotensin converting enzyme; CAD, coronary artery disease; MI, } \\
\text { myocardial infarction; NS, not significant; NYHA, New York Heart } \\
\text { Association; PTCA, percutaneous transluminal coronary angioplasty; } \\
\text { TIMI, thrombolysis in myocardial infarction. }\end{array}$} \\
\hline
\end{tabular}

\section{RESULTS}

\section{Baseline characteristics}

There were no significant differences in the basal clinical characteristics of the two groups as table 1 shows. According to the Killip classification, clinical presentation at the time of the index MI was similar in both groups, as was New York Heart Association classification at the time of PTCA. There were no differences in the use at baseline of cardioactive agents and other medications. Long term medical treatment was decided by the attending cardiologist. No differences were observed regarding the number of patients taking ACE inhibitors, $\beta$ blockers, or other cardioactive agents (table 1 ).

\section{Angiographic characteristics}

Table 2 shows the basal angiographic characteristics of the two groups. All patients had pre-PTCA TIMI grade 0 flow as a result of chronic total occlusion of the IRA. After PTCA, successful reperfusion with TIMI grade 3 flow was obtained

\begin{tabular}{llll} 
Table 2 & Angiographic characteristics & \\
\hline & $\begin{array}{l}\text { Group 1 } \\
(\mathbf{n}=\mathbf{3 5})\end{array}$ & $\begin{array}{l}\text { Group 2 } \\
(\mathbf{n}=\mathbf{3 0})\end{array}$ & p Value \\
\hline & & & \\
\hline $\begin{array}{l}\text { Extent of CAD } \\
\text { 1 vessel }\end{array}$ & $69 \%$ & $54 \%$ & NS \\
2 vessels & $23 \%$ & $34 \%$ & NS \\
3 vessels & $8 \%$ & $12 \%$ & NS \\
Occluded infarct related artery & & & \\
LAD & $50 \%$ & $55 \%$ & NS \\
LCx & $23 \%$ & $34 \%$ & NS \\
RCA & $27 \%$ & $21 \%$ & NS \\
Presence of collaterals & $57 \%$ & $67 \%$ & NS \\
\hline
\end{tabular}

LCx, left circumflex coronary artery; LAD, left anterior descending coronary artery; RCA, right coronary artery. 

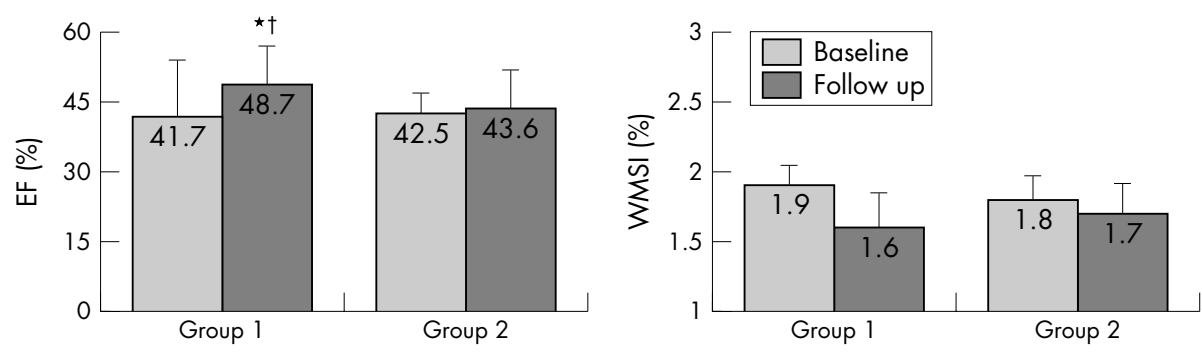

Figure 1 Ejection fraction (EF) and wall motion score index (WMSI) evaluated at baseline and at six months' follow up in the two groups of patients. Patients in group 1 had a significant ( $p<0.001)$ improvement in global and regional left ventricular function. ${ }^{*} p<0.001$ v baseline; $\uparrow p<0.001 v$ group 2.

in 35 patients (54\%, group 1), whereas TIMI 0-2 was obtained in 30 patients (46\%, group 2). In particular, technical success was obtained in 53 patients $(81.5 \%)$ and clinical success in 35 patients (54\%). Thus, PTCA was unsuccessful, with TIMI grade 0 flow, in only 12 patients $(18 \%)$ and resulted from the impossibility to cross the lesion with any guidewire. Finally, TIMI grade 1 flow was obtained in 12 patients (18\%) and TIMI 2 flow in six patients (9\%). Stents were implanted in all cases of successful PTCA to optimise the immediate and long term results. ${ }^{21} 22$

\section{Echocardiographic baseline characteristics}

Figures 1 and 2 show baseline echocardiographic characteristics. Global and regional LV function were similar in both groups (LVEF $41.7 \% \quad v \quad 42.5 \%$ in group 2, not significant; WMSI $1.9 v 1.8$ in group 2, not significant). No difference was observed in basal ventricular volumes between the groups (fig 2).

\section{Echocardiography at follow up}

Figures 1 and 2 show echocardiographic data at follow up. In group 1 global (LVEF $41.7 \% v 48.7 \%$ at follow up, $\mathrm{p}<0.001 v$ basal) and regional function (WMSI $1.9 \vee 1.6$ at follow up, $\mathrm{p}<0.001 v$ basal) improved significantly. Furthermore, LVEF at follow up was significantly higher in group 1 than in group $2(48.7 \% \vee 43.6 \%, p<0.001)$. Ventricular volumes also improved significantly in group 1 compared with basal values. Both EDVi $\left(75 v 92 \mathrm{ml} / \mathrm{m}^{2}, \mathrm{p}=0.001\right)$ and ESVi $(40 v$ $52 \mathrm{ml} / \mathrm{m}^{2}, \mathrm{p}=0.001$ ) were significantly reduced at follow up. Lastly, ventricular volumes in group 1 were significantly better than in group 2. Both EDVi $\left(75 \vee 86 \mathrm{ml} / \mathrm{m}^{2}\right.$ in group 2,

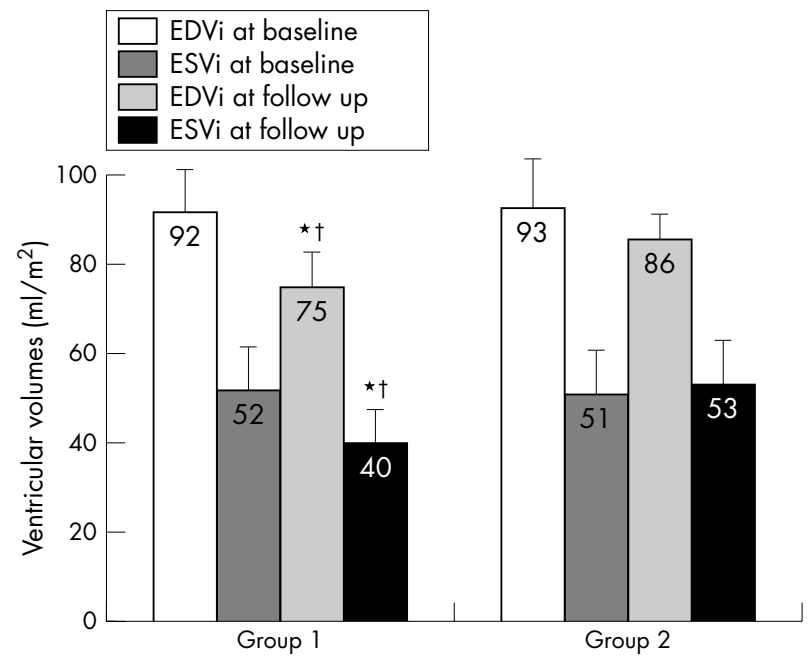

Figure 2 Indexed end systolic (ESVi) and end diastolic (EDVi) left ventricular volumes at baseline and at six months' follow up in the two groups of patients. Patients in group 1 had a significant reduction in left ventricular volumes at follow up with respect to baseline value and to group 2 at follow up. ${ }^{*} p=0.001 v$ baseline; $\uparrow p=0.011 v$ group 2 . $\mathrm{p}=0.011)$ and ESVi $\left(40 v 53 \mathrm{ml} / \mathrm{m}^{2}\right.$ in group 2, p = 0.011) at follow up were significantly smaller in group 1 than in group 2 .

\section{Clinical follow up}

Table 3 lists MACE. In group 2, there was a trend to a higher incidence of new MI and a significantly higher incidence of surgical revascularisation. In group 1 , two patients underwent new successful PTCA of the target vessel because of unstable angina. Of note, the incidence of cardiac deaths, all occurring within the first year after PTCA, was significantly higher in group 2; no cardiac death occurred in group 1 ( $13 \%$ $v 0 \%, \mathrm{p}<0.004)$. In particular, two patients $(6 \%)$ died suddenly at home (as reported by their family), one (3\%) died as a complication of acute heart failure, and one had a fatal MI. Furthermore, all cause mortality was significantly higher in the group $2(16.6 \% v 2.8 \%$, respectively, $\mathrm{p}<0.001)$. Thus, the overall rate of MACE was significantly higher in group 2 than in group $1(43 \% \vee 11 \%, p<0.01)$. Figure 3 depicts three year Kaplan-Meier event-free survival curves for cardiac death, the combined end point of cardiac death and new MI, and overall MACE. Multiple logistic regression analysis showed TIMI 3 flow after PTCA as the only independent predictor of improved survival (relative risk $0.091,95 \%$ confidence interval 0.015 to $0.575 ; p=0.011$ ).

\section{DISCUSSION}

The main finding of this study is that very late reopening of a chronically occluded IRA (six months after transmural MI) with optimal restoration of antegrade blood flow (TIMI 3) improves LV function and long term clinical outcome over a three year period preventing cardiac death. Although this study could not determine the mechanism of this benefit with certainty, the improvement in global and regional ventricular function and the observation that TIMI 3 flow after PTCA was a powerful and independent predictor of event-free survival support the contention that optimal reperfusion of the IRA also improves survival when obtained several months after a transmural MI.

\section{Late reperfusion: effects on LV function}

Several trials ${ }^{23}{ }^{24}$ have shown that LV function is the most important predictor of long term survival of patients with MI

Table 3 Major adverse cardiac events (MACE)

\begin{tabular}{lcll}
\hline & $\begin{array}{c}\text { Group } \mathbf{~} \\
(\mathbf{n = 3 5 )}\end{array}$ & $\begin{array}{l}\text { Group 2 } \\
(\mathbf{n = 3 0 )}\end{array}$ & p Value \\
\hline Cardiac death & $0 \%$ & $13 \%$ & $<0.004$ \\
Overall death & $2.8 \%$ & $16.6 \%$ & $<0.001$ \\
Ml & $3 \%$ & $10 \%$ & $\mathrm{NS}$ \\
Repeat PTCA & $6 \%$ & $0 \%$ & $\mathrm{NS}$ \\
CABG & $3 \%$ & $17 \%$ & $<0.05$ \\
CHF & $0 \%$ & $3 \%$ & $\mathrm{NS}$ \\
MACE & $11 \%$ & $43 \%$ & $<0.01$ \\
\hline \multirow{2}{*}{ CABG, coronary artery bypass grafting; CHF, congestive heart failure. }
\end{tabular}



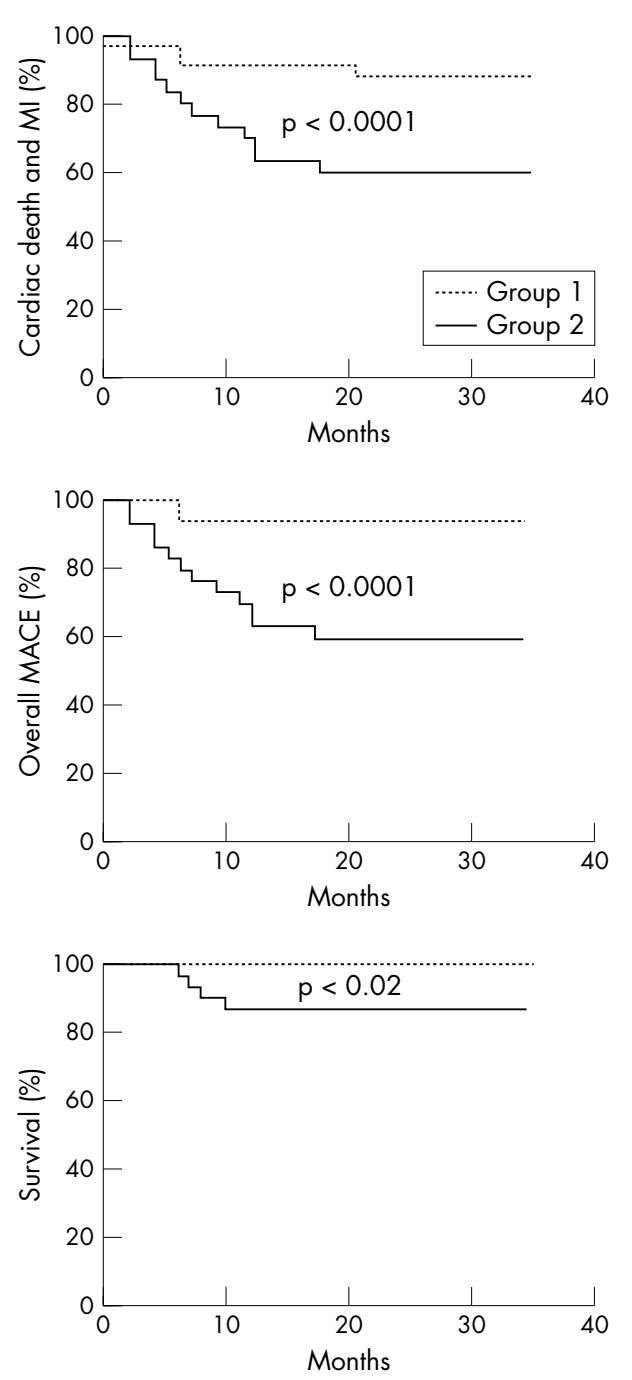

Figure 3 Three year Kaplan-Meier curves for cardiac death and myocardial infarction (MI), survival rate, and all major adverse cardiac events (MACE; cardiac death, acute MI, any target vessel revascularisation) in the two groups of patients. Group 1 had a significant reduction in the combined end point of cardiac death and $\mathrm{MI}$ $(p<0.0001)$, cardiac death alone $(p=0.02)$, and overall MACE $(p<0.0001)$ compared with group 2 .

and is closely related to early and complete reperfusion of the IRA. $^{12}$ Although experimental ${ }^{67}$ and clinical trials ${ }^{9}$ suggest that late restoration of flow reduces infarct size and prevents LV dilatation, it has not been determined whether late restoration of optimal reperfusion in the chronic phase (several months) after MI preserves LV function. Furthermore, recent studies ${ }^{14}{ }^{15}$ have shown a short time window of only 2-3 weeks during which the myocardium may still be salvaged and remodelling of LV can be prevented.

Horie and colleagues ${ }^{25}$ in a randomised trial reported that delayed PTCA (ranging from 24 hours to three weeks after MI) of a chronically occluded IRA after anterior MI reduced the rate of cardiac events and prevented LV dilatation over a period of five years compared with patients with persistent occlusion of the IRA. According to these studies, patients with a large anterior MI may benefit from late PTCA only if the IRA is reopened shortly after the acute event.

We showed in this study that end diastolic and end systolic volumes are significantly reduced in patients with reopened chronically occluded IRA six months after PTCA as compared with patients with an occluded IRA. Similarly, LVEF and
WMSI were significantly improved in patients with a reopened IRA. Although additional benefit may originate from the treatment of a non-culprit vessel, recovery takes place mostly in regions supplied by the treated artery and is not present in patients with an occluded artery after PTCA. Taken together these data suggest that dysfunctional but viable myocardium may persist several months after acute MI, suggesting that optimal antegrade flow in the IRA may restore the persistent hibernating myocardium leading to recovery of LV function and preventing ventricular dilatation and cardiac death. Furthermore, complete revascularisation may add a beneficial effect contributing to recovery of global ventricular function. The improvement of regional and global LV function leads to a significantly better long term clinical outcome with reduction of cardiac death and overall MACE in group 1.

\section{Possible mechanisms of beneficial effects of late reperfusion}

The late reopening of an occluded IRA may improve LV function provided viable myocardium ${ }^{15} 25$ is present within the zone supplied by the artery. Available data suggest that viable myocardium can survive only a few weeks after an acute event. Collateral flow may prolong this time window by the so called hibernating myocardium. ${ }^{15} 2627$ In patients after up to five weeks of an MI and with chronically occluded IRA, it was shown that patients with collateral flow had an improved regional LV function after restoration of IRA patency by PTCA and that the extent of recovery was related to the extension of collaterals. ${ }^{28}$ There is probably little to gain in re-establishing flow in a chronically occluded IRA supplying a thin, scarred area of myocardium. However, if the IRA has occluded slowly, developing collaterals artery, and myocardial viability has been maintained by these collaterals, re-establishing blood flow to that segment provides the opportunity for considerable benefit from a pathophysiological perspective ${ }^{29}$

The occurrence of angina in the setting of significant LV dysfunction has also been reported to indicate a possible beneficial effect of revascularisation on survival rate. ${ }^{30}$ In our study, all patients had either the symptoms of ischaemia or documented myocardial viability, and there was a similar high rate of collateral circulation in both groups. Furthermore, baseline demographic features and clinical presentation were similar in both groups. Lastly, LV function was similar at baseline in both groups. Of critical importance is the independent effect of TIMI 3 flow after PTCA on survival. The presence in the model of multiple logistic regression analysis of collateral circulation, clinical features, and an index of ventricular function at baseline may exclude any confounding effect of these variables on survival. Thus, our data seem to suggest that improved LV function and the long term clinical outcome may be the consequence of recovered hibernating myocardium in patients with optimal reperfusion of the chronically occluded IRA. Although our data cannot support with certainty that reopening a chronically occluded IRA reduces death related to heart failure or major arrhythmias, $75 \%$ of cardiac deaths in our population were related to sudden death and acute heart failure. Thus, we can speculate that the benefit in terms of long term survival in patients with a reopened chronically occluded IRA is related to a reduced risk of developing major arrhythmias or heart failure. Accordingly, patency of the IRA has also been suggested to confer electrical stability to the infarct area, ${ }^{31}{ }^{32}$ thereby reducing the risk of arrhythmia by modifying the autonomic balance through a reduction of sympathetic activation and recovery of the protective vagal tone. 
Olivari and colleagues ${ }^{33}$ and Suero and associates ${ }^{34}$ have recently reported that patients with successful reopening of chronically occluded coronary vessels have a better long term outcome than those undergoing a failed procedure. In their studies $70 \%$ and $50 \%$, respectively, of patients had a previous acute MI and in both studies the only variable associated with a better long term clinical outcome was the initially successful PTCA. Surgical revascularisation after a failed procedure reverted the otherwise poorer clinical outcome only when performed within 30 days. There are other possible mechanisms by which the patency of the IRA may potentially influence clinical evolution independently of myocardial salvage. ${ }^{89}$ Reperfusion may cause haemorrhage and contraction band necrosis that increase the stiffness of the infarct zones or provide a sort of scaffolding, which limits LV dilatation after MI. ${ }^{35}$

\section{Study limitations}

This was a single centre non-randomised study with a relatively small sample size. Furthermore, coronary angiography was not repeated at follow up; thus, restenosis could not be excluded. However, the goal of the study was to evaluate clinical outcome and there were no clinical events to suggest reocclusion or restenosis. All patients in the current study had ischaemic symptoms or either ischaemia or myocardial viability in the territory subtended by the chronically occluded IRA. Thus, according to Bounous and colleagues $^{36}$ and Allman and associates, ${ }^{37}$ these two features strongly suggested revascularisation of the chronically occluded IRA. However, many patients with a chronically occluded IRA have no evidence of myocardial ischaemia related to the occlusion of the vessel itself or of myocardial viability. Thus, the benefit to $\mathrm{LV}$ function and long term clinical outcome after PTCA observed in this study cannot be extrapolated to patients without evidence of ischaemia or viability. Lastly, almost half the patients had TIMI $<3$ flow after PTCA and thus clinical success was low. However, success is only related to the assumed restricted definition of clinical success. In fact, considering technical success, our rate of success is not far from the current rate of procedural success in reopening chronic total occluded coronary artery. Again, since this is not a randomised study, we cannot exclude that no attempt might have been better than a failed attempt at reopening a chronically occluded IRA.

\section{Clinical implications}

Our study shows that late restoration (six months after an acute event) of IRA patency may improve LV function, prevent LV dilatation, and reduce cardiac death. This should be taken into consideration in making clinical decisions and is yet another issue for the open artery hypothesis. Furthermore, in a recent randomised trial (DECOPI (désobstruction coronaire en post-infarctus)), Steg and colleagues $^{38}$ showed that, although routinely late (2-15 days after acute MI) recanalisation of an IRA provided only little clinical benefit, patients with effective recanalisation, persisting at six months' angiography, had improved LVEF and reduced mortality. Thus, considering these beneficial effects, all clinical and diagnostic efforts should be made to identify patients who may gain most from a strategy of reopening a chronically occluded IRA.

\footnotetext{
Authors' affiliations

F Piscione, G Galasso, G De Luca, G Marrazzo, G Sarno, O Viola, D Accardo, M Chiariello, Department of Cardiology, Federico II University, Naples, Italy
}

\section{REFERENCES}

1 GUSTO Angiographic Investigators. The effects of tissue plasminogen activator, streptokinase, or both on coronary-artery patency, ventricular function, and survival after acute myocardial infarction. The GUSTO angiographic investigators. N Engl J Med 1993;329:1615-22.

2 Vogt A, von Essen R, Tebbe $U$, et al. Impact of early perfusion status of the infarct-related artery on short-term mortality after thrombolysis for acute myocardial infarction: retrospective analysis of four German multicenter studies. J Am Coll Cardiol 1993;21:1391-5.

3 TIMI Study Group. The thrombolysis in myocardial infarction (TIMI) trial: phase I findings. TIMI study group. N Engl J Med 1985;312:932-6.

4 GISSI Investigators. Effectiveness of intravenous thrombolytic treatment in acute myocardial infarction. Gruppo Italiano per lo Studio della Streptochinasi nell'Infarto Miocardico (GISSI). Lancet 1986;i:397-402.

5 GUSTO Investigators. An international randomized trial comparing four thrombolytic strategies for acute myocardial infarction. The GUSTO investigators. N Engl J Med 1993;329:673-82.

6 Hochman JS, Choo H. Limitation of myocardial infarct expansion by reperfusion independent of myocardial salvage. Circulation 1987;75:299-306.

7 Hale SL, Kloner RA. Left ventricular topographic alterations in the completely healed rat infarct caused by early and late coronary artery reperfusion. Am Heart J 1988;1 16:1508-13.

$8 \mathrm{Kim}$ CB, Braunwald E. Potential benefits of late reperfusion of infarcted myocardium: the open artery hypothesis. Circulation 1993;88:2426-36.

9 Braunwald E. Myocardial reperfusion, limitation of infarct size, reduction of left ventricular dysfunction, and improved survival: should the paradigm be expanded? Circulation 1989;79:441-4.

10 Topol EJ, Califf RM, Vandormael M, et al. A randomized trial of late reperfusion therapy for acute myocardial infarction. Thrombolysis and Angioplasty in Myocardial Infarction-6 Study Group. Circulation 1992;85:2090-9.

11 LATE Study Investigators. Late assessment of thrombolytic efficacy (LATE) study with alteplase 6-24 hours after onset of acute myocardial infarction. Lancet 1993;342:759-66.

12 Sabri MN, DiSciascio G, Cowley MJ, et al. Immediate and long-term results of delayed recanalization of occluded acute myocardial infarction-related arteries using coronary angioplasty. Am J Cardiol 1992;69:575-8.

13 Dzavik V, Beanlands DS, Davies RF, et al. Effects of late percutaneous transluminal coronary angioplasty of an occluded infarct-related coronary artery on left ventricular function in patients with a recent (6 weeks) Q-wave acute myocardial infarction (total occlusion post-myocardial infarction intervention study [TOMIIS]: a pilot study). Am J Cardiol 1994;73:856-61.

14 Pizzetti G, Belotti G, Margonato A, et al. Coronary recanalization by elective angioplasty prevents ventricular dilation after anterior myocardial infarction. J Am Coll Cardiol 1996;28:837-45.

15 Pfisterer ME, Buser P, Osswald S, et al. Time dependence of left ventricular recovery after delayed recanalization of an occluded infarct-related coronary artery: findings of a pilot study. J Am Coll Cardiol 1998;32:97-102.

16 Piscione F, Perrone-Filardi P, De Luca G, et al. Low dose dobutamine echocardiography for predicting functional recovery after coronary revascularisation. Heart 2001;86:679-86.

17 Chesebro JH, Knatterud G, Roberts R, et al. Thrombolysis in myocardial infarction (TIMI) trial, phase I: a comparison between intravenous tissue plasminogen activator and intravenous streptokinase: clinical findings through hospital discharge. Circulation 1987;76:142-54.

18 Rentrop KP, Thornton JC, Feit F, et al. Determinants and protective potential of coronary arterial collaterals as assessed by an angioplasty model. Am J Cardiol 1988;61:677-84.

19 Starling MR, Crawford MH, Sorensen SG, et al. Comparative accuracy of apical biplane cross-sectional echocardiography and gated equilibrium radionuclide angiography for estimating left ventricular size and performance. Circulation 1981;63:1075-84.

20 Feigenbaum H. Digital recording, display, and storage of echocardiograms. $J$ Am Soc Echocardiogr 1988;1:378-83.

21 Moussa I, Di Mario C, Moses J, et al. Comparison of angiographic and clinical outcomes of coronary stenting of chronic total occlusions versus subtotal occlusions. Am J Cardiol 1998;81:1-6.

22 Piscione F, Galasso G, Maione A, et al. Immediate and long term outcome of recanalization of chronic total coronary occlusions. J Interv Cardiol 2002;15:1-7.

23 Miketic S, Carlsson J, Tebbe U. Improvement of global and regional left ventricular function by percutaneous transluminal coronary angioplasty after myocardial infarction. J Am Coll Cardiol 1995;25:843-7.

24 White HD, Norris RM, Brown MA, et al. Left ventricular end-systolic volume as the major determinant of survival after recovery from myocardial infarction. Circulation 1987;76:44-51.

25 Horie H, Takahashi M, Minai K, et al. Long-term beneficial effect of late reperfusion for acute anterior myocardial infarction with percutaneous transluminal coronary angioplasty. Circulation 1998;98:2377-82.

26 Fath-Ordoubadi F, Beatt KJ, Spyrou N, et al. Efficacy of coronary angioplasty for the treatment of hibernating myocardium. Heart 1999;82:210-6.

27 Ross J Jr. Myocardial perfusion-contraction matching: implications for coronary heart disease and hibernation. Circulation 1991;83:1076-83.

28 Sirnes PA, Golf S, Myreng Y, et al. Stenting in chronic coronary occlusion (SICCO): a randomized, controlled trial of adding stent implantation after successful angioplasty. J Am Coll Cardiol 1996;28:1444-51. 
29 Sabia PJ, Powers ER, Ragosta M et al. An association between collateral blood flow and myocardial viability in patients with recent myocardial infarction. N Engl J Med 1992;327:1825-31.

30 McCullough PA, Sullivan R. Equipoise on opening chronic total occlusions. J Interv Cardiol 2002;15:243-7.

31 Lange RA, Cigarroa RG, Wells PJ, et al. Influence of anterograde flow in the infarct artery on the incidence of late potentials after acute myocardial infarction. Am J Cardiol 1990;65:554-8.

32 Boehrer JD, Glamann DB, Lange RA, et al. Effect of coronary angioplasty on late potentials one to two weeks after acute myocardial infarction. Am J Cardiol 1992;70:1515-9.

33 Olivari Z, Rubartelli P, Piscione F, et al. Immediate results and one year clinical outcome after percutaneous coronary intervention in chronic total occlusion. J Am Coll Cardiol 2003:41:1672-8.

34 Suero JA, Marso SP, Jones PG, et al. Procedural outcomes and long term survival among patients undergoing percutaneous coronary intervention of a chronic total occlusion in native coronary arteries: a 20 year experience. J Am Coll Cardiol 2001;38:409-14.

35 Danchin N, Angioi M, Cador R, et al. Effect of late percutaneous angioplastic recanalization of total coronary artery occlusion on left ventricular remodeling, ejection fraction, and regional wall motion. J Am Coll Cardiol 1996:78:729-35

36 Bounous EP, Mark DB, Pollok BG, et al. Surgical survival benefits for coronary disease patients with left ventricular dysfunction. Circulation 1988:78:1151-7.

37 Allman KC, Shaw $\sqcup$, Hachamovitch R, et al. Myocardial viability testing and impact of revascularization on prognosis in patients with coronary artery disease and left ventricular dysfunction: a meta analysis. J Am Coll Cardiol 2002;39:1151-8.

38 Steg PG, Thuaire C, Himbert D, et al. Impact of an open artery late after infarction: angiographic results of the DECOPI randomized trial [abstract]. J Am Coll Cardiol 2004;275A(suppl):815.

\section{IMAGES IN CARDIOLOGY}

doi: $10.1136 /$ hrt.2004.049593

\section{Brugada syndrome precipitated by a tricyclic antidepressant}

A 42 year old man with a history of depression, asthma, and obstructive sleep apnoea presented with ventricular fibrillation at home. On admission to hospital, his medications were desipramine $400 \mathrm{mg}$ at night time, omeprazole $20 \mathrm{mg}$ daily, and bromocriptine $2.5 \mathrm{mg}$ at night time. One month before admission, his desipramine dose had been increased from $300 \mathrm{mg}$. He denied suicidal ideation or drug overdose, street drug use, or other non-prescription drug use. Two years before his presentation an ECG was normal (panel A). His medications at that time were: fluoxetine $100 \mathrm{mg}$ daily, omeprazole $20 \mathrm{mg}$ daily, and moclobemide $300 \mathrm{mg}$ three times daily. His presenting ECG (panel B) was significantly different from his previous ECG. His admission electrolytes and thyroid stimulating hormone (TSH) were normal. In hospital, the patient had two other episodes of ventricular fibrillation. His coronary angiogram was normal. Gated blood pool SPECT confirmed that his right and left ventricular ejection fractions were normal. There was no evidence of arrhythmogenic right ventricular dysplasia on magnetic resonance imaging. Genetic testing revealed an SCN5A polymorphism (His558Arg). Desipramine was discontinued and his ECG returned to normal (panel C). He was treated with a $\beta$ blocker and an implantable cardioverterdefibrillator. He has had no recurrent ventricular arrhythmia since his desipramine was discontinued (three months follow up). The Brugada ECG revealed by tricyclic antidepressants have been previously described. However this is the first report of the Brugada syndrome (that is, Brugada ECG and life threatening ventricular arrhythmias) being provoked by a

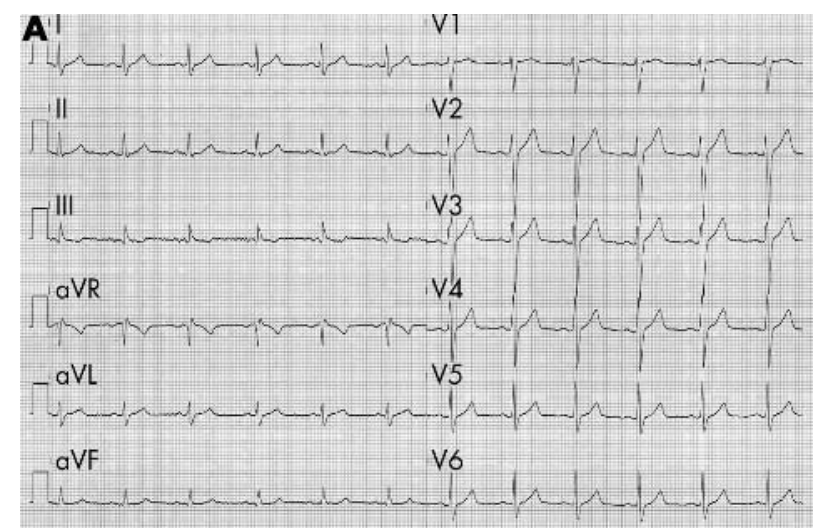

tricyclic antidepressant. The relevance of the SCN5A polymorphism in the presence of desipramine induced Brugada syndrome is unknown, although subclinical genetic polymorphisms have been identified in other drug associated ventricular arrhythmias. To our knowledge, this is the first report of the Brugada syndrome being induced by a drug other than an antiarrhythmic.

B J W Chow $M$ Gollob

D Birnie bchow@ottawaheart.ca
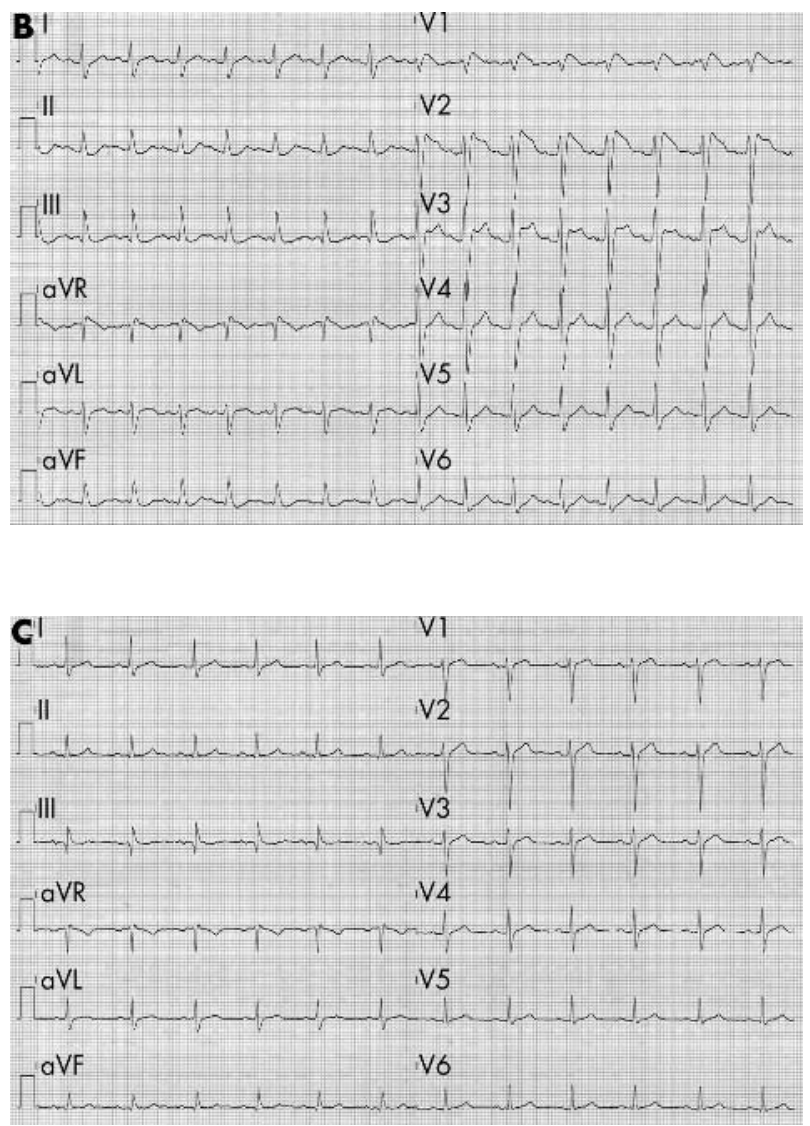